\title{
Experimental sulfate amendment alters peatland bacterial community structure
}

Strickman, R. J. S. ${ }^{a}$, Fulthorpe, R.R. ${ }^{\text {a }}$, Coleman Wasik, J.K. ${ }^{\text {b,1 }}$, Engstrom, D.R. ${ }^{\text {, }}$, and Mitchell, C.P.J. ${ }^{a^{*}}$

Department of Physical and Environmental Sciences, University of Toronto Scarborough, Scarborough, Ontario, Canada ${ }^{\text {a }}$, St. Croix Watershed Research Station, Science Museum of Minnesota, Marine on St. Croix, Minnesota, United States ${ }^{\mathrm{b}}$

*Address correspondence to Carl Mitchell, carl.mitchell@mail.utoronto.ca.

${ }^{1}$ Present address: Department of Plant and Earth Science, University of Wisconsin-River Falls, River Falls, Wisconsin 54022, United States 


\begin{abstract}
As part of a long-term, peatland-scale sulfate addition experiment, the impact of varying sulfate deposition on bacterial community responses was assessed using $16 \mathrm{~S}$ tag encoded pyrosequencing. In three separate areas of the peatland, sulfate manipulations included an eight year quadrupling of atmospheric sulfate deposition (experimental), a 3-year recovery to background deposition following 5 years of elevated deposition (recovery), and a control area. Peat concentrations of methylmercury $(\mathrm{MeHg})$, a bioaccumulative neurotoxin, were measured, the production of which is attributable to a growing list of microorganisms, including many sulfate-reducing Deltaproteobacteria. The total bacterial and Deltaproteobacterial community structures in the experimental treatment differed significantly from those in the control and recovery treatments that were either indistinguishable or very similar to one another. Notably, the relatively rapid return (within three years) of bacterial community structure in the recovery treatment to a state similar to the control, demonstrates significant resilience of the peatland bacterial community to changes in atmospheric sulfate deposition. Changes in $\mathrm{MeHg}$ accumulation between sulfate treatments correlated with changes in the Deltaproteobacterial community, suggesting that sulfate may affect $\mathrm{MeHg}$ production through changes in the community structure of this phylum.
\end{abstract}

Keywords: wetland, microbial ecology, sulfate reducing bacteria, mercury, methylmercury

\title{
1. Introduction
}

Atmospheric sulfate deposition may exert a significant impact on bacterial community structure and activity in anoxic, aquatic ecosystems. Sulfate is an electron acceptor for sulfate reducing 
bacteria (SRB), whose by-products affect the growth of other metabolic guilds including sulfide oxidizers and, under some conditions, methanogens (Muyzer and Stams, 2008; Pester, 2012). Peatlands, which extend over more than four million square kilometres and store up to $30 \%$ of the world's soil carbon (Limpens et al., 2008), host diverse and active communities of SRB, even in the upper, periodically unsaturated layers (Schmalenberger et al., 2007) that are the most exposed to atmospheric inputs. Although changes in sulfate deposition have the potential to alter interactions among peatland bacteria, and thus affect major biogeochemical cycles and ecosystem functioning (Fuhrman 2009), sulfate as a bacterial driver has been little studied in comparison to the effects of other atmospherically deposited nutrients on bacterial communities (Andersen et al., 2013). Previous investigations have focused on very broad taxonomic or metabolic divisions, and indicate an increase in gram-negative bacteria (Pennanen et al., 1998), stimulation of SRB paired with inhibition of methanogens (Gauci and Chapman, 2006; Vile et al., 2003), or similarities in the diversity of a limited number of SRB from sites that received similar levels of nutrients, including sulfate (Steger et al., 2011). Here high-throughput DNA sequencing was used to investigate the influence of sulfate on the peatland bacterial community as a whole..

The response of bacterial communities to disturbance, including changes in atmospheric nutrient supply, is an important and variable aspect of bacterial ecology (Griffiths and Philippot, 2012). Bacterial communities may resist or rapidly recover from some disturbances (Allison and Martiny, 2008), while in other circumstances a disturbance may trigger a long-term change in bacterial community structure (McKew et al., 2011; Nelson et al., 2015) or functioning (Currey et al., 2009), analogous to a shift to an alternative stable state (Scheffer et al., 2001). In a shortterm experimental manipulation of sulfate deposition in an ombrotrophic peatland, slight shifts in microbial enzyme activities were observed in an area of the peatland recovering from sulfate 
additions (Seifert-Monson et al., 2014), but the effects of sulfate on bacterial community structure remain unknown.

In much of Europe and North America, atmospheric deposition of sulfate has greatly increased since the onset of the industrial revolution (Mayewski et al., 1990), although stricter emissions regulations introduced in the 1980s have substantially decreased sulfate deposition in these same regions (Kahl et al., 2004). Sulfate deposition to aquatic systems such as lakes and wetlands is of particular significance because it has been repeatedly observed to increase levels of methylmercury (MeHg). $\mathrm{MeHg}$ is a bioaccumulative neurotoxin that is produced by bacteria in permanently or transiently anoxic aquatic environments (Branfireun et al., 1990; Coleman Wasik et al., 2012; Munthe et al., 2007). Peatlands are a wetland type wherein particularly high production and accumulation of $\mathrm{MeHg}$ is often observed in periodically inundated near-surface layers (Mitchell et al., 2008). Mercury (Hg) methylation ability has been confirmed in many Deltaproteobacterial SRB (Gilmour et al., 2013; Ranchou-Peyruse et al., 2009), and experimental sulfate additions have been shown to increase $\mathrm{MeHg}$ concentrations via metabolic stimulation of SRB (Gilmour et al., 1992; Yu et al., 2010). However, outside of the direct metabolic stimulation of SRB, it is not known if sulfate-mediated changes in bacterial community structure relate to net $\mathrm{MeHg}$ production, which could potentially occur via syntrophic interactions between methylating and nonmethylating taxa (Bae et al., 2014; Pak and Bartha, 1998).

In this study, the in situ response of the bacterial community of a sub-boreal peatland in Minnesota to relatively long-term experimental increases and decreases in sulfate deposition, along with the associated changes in $\mathrm{MeHg}$ concentrations were assessed. The primary objective here was to assess how changing sulfate loading influences the composition of the peatland bacterial community, with a secondary aim to determine if any relationship exists between $\mathrm{MeHg}$ 
accumulation within the peat and bacterial community structure. It is hypothesized that increased sulfate loading will lead to significant changes in the peatland bacterial community composition. Given the relatively rapid declines in $\mathrm{MeHg}$ concentrations observed by Coleman Wasik et al. (2012) once experimental sulfate additions were ceased in this same study wetland, it is hypothesized that the bacterial community structure will also change relatively rapidly with decreased sulfate loading and that changes in bacterial community structure can be related to changes in $\mathrm{MeHg}$ accumulation and loss.

\section{Experimental Procedures}

\subsection{Site Description and Experimental Design}

An 8-year manipulation of an experimental sub-boreal peatland in the Marcell Experimental Forest, Minnesota $\left(47^{\circ} 32^{\prime} \mathrm{N}, 93^{\circ} 28^{\prime} \mathrm{W}\right)$ simulated realistic increases in sulfate deposition as well as recovery from augmented sulfate deposition, and the impact of these changes on net $\mathrm{MeHg}$ accumulation (Coleman Wasik et al., 2012, 2015; Jeremiason et al., 2006). The peatland, referred to as "S6", covers approximately 2.4 ha and includes an ombrotrophic, elongate, 10-25 m wide center (bog) with Sphagnum hummocks and an overstory of tamarack (Larix lariciana) and black spruce (Picea mariana). The bog has a 2-10 m wide margin (lagg) vegetated with alders (Alnus rugosa) and willows (Salix spp.; Figure 1). In addition to direct precipitation inputs, the lagg intermittently receives water via shallow interflow from a surrounding 6.5 ha upland forest, whereas the bog area is precipitation fed only (Mitchell et al., 2009). Sulfate deposition to a portion of the S6 peatland was experimentally increased by $\sim 4 \mathrm{x}$ over ambient rates in order to simulate the deposition received by areas in the northeastern US and eastern Canada before strict emissions regulations came into effect in the 1980s. Source water for the additions was obtained 
from a dilute (conductivity $\sim 10 \mu \mathrm{S} \mathrm{cm}^{-1}$ ), low mercury $\left(\mathrm{Hg}<1 \mathrm{ng} \mathrm{l}^{-1}\right.$ ) ombrotrophic pond in an adjacent watershed and amended with concentrated sodium sulfate to a final sulfate concentration of $\sim 200 \mathrm{mg} \mathrm{l}^{-1}$, as described previously in Jeremiason et al. (2006) and Coleman Wasik et al. (2012). From spring of 2001 to fall of 2008, this system was used to deliver $32 \mathrm{~kg}$ $\mathrm{ha}^{-1} \mathrm{yr}^{-1}$ of sulfate to both the bog and lagg areas of an experimental section of the wetland via a PVC pipe sprinkler system during 3-4 simulated rainfall events $(6-10 \mathrm{~mm})$ per year. An unamended area of the peatland, hydrologically up-gradient of the experimental area, was maintained as a control (Figure 1). In 2006, sulfate additions to the up-gradient one-third of the experimental section ended, creating a recovery treatment subject only to an average background deposition rate of $4.6 \mathrm{~kg} \mathrm{ha}^{-1}$ (NADP, 2006). Additions to the downstream two-thirds of the experimental section continued through the end of 2008 with a final sulfate amendment in October. In addition to this three-level sulfate amendment factor (experimental, recovery, and control), the natural topography of the peatland created another two-level factor (ombrotrophic bog area versus the slightly more minerotrophic lagg area), for a total of six treatments (Figure 1) that could be sampled to compare the effects of sulfate deposition on the bacterial community as well as the concentration of $\mathrm{MeHg}$ in the peat.

In late-May 2009, a period when the water table was above the peat surface, three peat cores were collected in each of the six treatment areas described above, with each core serving as a replicate. From each of these eighteen cores, peat was collected from the $2-4 \mathrm{~cm}$ depth interval and kept frozen until analysis. Peat samples from each core were split into two subsamples for analyses of 1) bacterial community composition and 2) total $\mathrm{Hg}(\mathrm{THg})$ and $\mathrm{MeHg}$ concentrations, according to methods described below.

\subsection{Bacterial analyses}




\subsubsection{DNA extraction and sequencing}

Total community genomic DNA was extracted from each of the three replicate samples from all six treatment areas (18 samples total). Using the MoBio PowerSoil ${ }^{\mathrm{TM}}$ DNA Extraction Kit (MO BIO Laboratories, Solana Beach, CA, USA), DNA was extracted from $0.25 \mathrm{~g}$ of thawed peat according to the manufacturer's instructions. An Eppendorf Nanodrop 1000 (Thermo Scientific) was used to estimate DNA concentration $\left(n g \mu^{-1}\right)$ and purity (260/280 and 260/230 ratios). These eighteen samples were subjected to pyrosequencing of bacterial $16 \mathrm{~S}$ ribosomal gene amplicon. The hypervariable V1-V3 region was targeted using 28f (5'-GAGTTGATCNTGGTCAG-3') and 519r (5'-GTNTTACNGCGGCKGCTG-3') (Amann et al., 1995) by bTEFAP (bacterial tag encoded FLX amplicon pyrosequencing), carried out by Research and Testing Inc. (Lubbock, Texas) on a Roche 454 FLX Titanium genome sequencer. Sequences were processed using Qiime 1.4.0. (Caporaso et al., 2010). Samples were demultiplexed, forward and (if present) reverse primers were trimmed. Low quality samples were identified and filtered out using the default parameters. Sequences were chimera filtered and denoised using OTUpipe with USEARCH (Edgar, 2010) and both de novo and database (GOLD) based chimera filtering with intersection; MINSIZE was 2. Sequences were assigned to operational taxonomic units (OTUs) at an identity threshold of 97\% (Kunin et al., 2010) using the RDP method trained on the Feb 4, 2011 release of Greengenes with default settings. Sequences were aligned using PYNAST trained against the 2011 release of the Greengenes core set, and a phylogenetic tree constructed with FASTTREE algorithm (Price et al., 2010) and default settings. To allow comparison of community compositions between samples that returned different numbers of reads, all community analyses were carried out on weighted abundances, calculated as the number of reads per OTU in a given sample divided by the total number of reads for that sample. 


\subsubsection{Sequence accession numbers}

All sequences that passed quality control steps and were included in the analysis were deposited to the EMBL-EBI database under accession numbers ERS452350-ERS452367.

\subsubsection{Sequence analysis}

To assess the impact of the varying sulfate treatments on the bacterial community, weighted UNIFRAC distance matrices, a phylogenetically aware beta diversity metric designed for analysis of large genomic datasets (Lozupone and Knight, 2005), were used to compare the relatedness of bacterial community composition from different treatments. Based on differences in hydrology and nutrient status (Mitchell et al., 2008), the bacterial communities of lagg and bog sites were analysed separately. Hierarchical clustering was applied to UNIFRAC matrices to visualize patterns of relatedness between bacterial communities (Hamady et al., 2009), and PERMANOVA (permutational analysis of variance) to assess the significance of the revealed patterns (Anderson, 2001; McArdle and Anderson, 2001). Alpha diversity was assessed using the Chao1 diversity index, which estimates the true diversity of a population by extrapolating from the abundance distribution of the subsample (Chao, 1984). Mantel tests were used to test correlations between bacterial community structures and peat $\mathrm{MeHg}$ content. These tests were conducted in Qiime with 999 permutations at $\alpha<0.05$. In addition, the Deltaproteobacteria, which host many SRB and confirmed mercury methylators, were separately assessed for the relationship of their community structure to sulfate amendment and $\% \mathrm{MeHg}$ (percent of $\mathrm{THg}$ as $\mathrm{MeHg}$ ) via the same methods used for the whole bacterial community. Two-tailed tests of Pearson's correlations at $\alpha \leq 0.01$ were used to relate specific OTUs with \% $\mathrm{MeHg}$ in peat.

\subsection{Chemical Analyses}


As for the bacterial community analyses, one peat sample was analysed from each of three cores collected from each of the six treatment areas, yielding 18 samples. THg analysis in peat samples was carried out via microwave digestion in concentrated $\mathrm{HNO}_{3}$, cold-vapor generation (using $\mathrm{SnCl}_{2}$ ), dual gold-trap amalgamation, and detection by cold vapor atomic fluorescence spectroscopy (CVAFS) on a Tekran 2600 total-Hg analyser. MeHg analysis was carried out via isotope dilution-gas chromatography-inductively coupled plasma mass spectrometry (ID-GCICPMS) after the method of Hintelmann et al. (1997). Samples were enriched with a known spike of $\mathrm{Me}^{199} \mathrm{Hg}$ and distilled in $8 \mathrm{M} \mathrm{H}_{2} \mathrm{SO}_{4}$ and $20 \% \mathrm{KCl}$ in acid-cleaned Teflon vessels (Horvat et al., 1993). MeHg in distillates was liberated from solution through aqueous phase ethylation with sodium tetraethylborate, concentrated on a Tenax trap, thermally desorbed in a stream of argon gas, and passed through a heated chromatography column hyphenated to an Agilent Technologies 7700x ICP-MS machine. Blanks, duplicates, and certified reference materials (MESS-3 for THg; IAEA-405 for MeHg) were used for ongoing quality control (Supplementary Table 1). Porewater for sulfate analysis was collected using a mini Teflon piezometer and peristaltic pump, and analysed using a Dionex DX-500 ion chromatograph with standard methods (Coleman Wasik et al., 2012). Porewater sulfate concentrations were assessed once per treatment in 2009 at the time of core collection and interpretations were supplemented with historical data taken from the treatment areas by Coleman Wasik et al. (2012 and 2015).

\section{Results and Discussion}

\subsection{Sulfate Deposition Manipulation Effects}

In this same peatland, experimental increases in sulfate deposition resulted in peak pore water sulfate concentrations (3.8 $\pm 2.2 \mathrm{mg} \mathrm{l}^{-1}$ in 2008) immediately following experimental additions, 
declining significantly over a period of approximately two weeks, but with concentrations remaining elevated above those observed in the control (Coleman Wasik et al., 2012, 2015). Sulfate concentrations in the recovery treatment porewaters declined to levels similar to those in the control $\left(<1 \mathrm{mg} \mathrm{l}^{-1}\right)$ by early 2006 , the first year without experimental sulfate addition to the recovery treatment area, although sulfate release after drought events continued to be elevated in the recovery treatment area for the remainder of the study, suggesting that strong internal sulfur cycling persisted in the recovery treatment area and likely through the time that samples from this study were collected (Coleman Wasik et al., 2012, 2015). Sulfate reduction is clearly sulfatelimited in this peatland, with relatively rapid conversion of sulfate to sulfide and subsequent accumulation into the reduced and organic sulfur pools within the peat (Coleman Wasik et al., 2012). During porewater sampling in spring 2009, concomitant with peat collection for this study, sulfate concentrations were highest in the experimental treatment in both bog $\left(2.99 \mathrm{mg} \mathrm{l}^{-1}\right)$ and lagg $\left(1.57 \mathrm{mg} \mathrm{l}^{-1}\right)$ areas and lowest in the control treatment area (bog: $1.09 \mathrm{mg} \mathrm{l}^{-1}$, lagg: 0.98 $\mathrm{mg} \mathrm{l}^{-1}$ ) with recovery area levels nearly identical to concentrations in the control area (Figure 2). Due to difficulty in collecting porewaters, only a single measurement was collected in each treatment, but the overall pattern of sulfate levels closely mirrors the long-running patterns observed in this experimental system (Coleman Wasik et al., 2012, 2015). These results were extensively explored by Coleman Wasik et al. $(2012,2015)$ and suggest that the sulfur cycle in the experimental area was significantly altered by sulfate additions, whereas sulfur cycling in the recovery area had more closely returned to pre-disturbance conditions.

\subsection{Bacterial Community Description}


A total of 241700 raw sequences were obtained from 18 core samples, 44038 of which were removed due to low read quality or during sample denoising and chimera filtering, leaving 197662 high quality sequences (8662-13110 per sample). Sequences clustered into 7050 operational taxonomic units (OTUs). Between 1480 and 2270 OTUs were obtained from each sample. The bacterial communities of the S6 peatland were diverse and harbored many rare taxa. Of the final 7050 OTUs, 29 were not of bacterial origin and 916 could not be assigned past the rank of Bacteria. Thirty phyla, 63 identified classes, 86 identified orders, and 109 identified families were represented in the sequences. Of the 5497 OTUs that could be assigned to the order level, 978 were placed into undescribed novel orders. Undescribed families made up 40\% (1936) of the 4889 OTUs that could be assigned to this level. Sixteen phyla were rare, representing less than $1 \%$ of any sample and 12 were completely absent from at least one treatment. The most abundant phylum was Proteobacteria, representing on average $30-52 \%$ of the weighted total community in each treatment, which included the classes Alphaproteobacteria $(21-36 \%)$, Betaproteobacteria (0.10-3.0\%), Deltaproteobacteria (2.5-6.6\%), Gammaproteobacteria $(3.6-7.6 \%)$ and unassigned Proteobacteria $(0.31-1.1 \%)$. Thirteen other phyla represented on average more than $1 \%$ of the total community in any treatment (Figure 3a), with the most commonly detected families being Acidobacteraceae, Bradyrhizobiaceae, Hyphomicrobiaceae, two other undefined families in Rhizobiales, and Acetobacteraceae in Rhodospiralles (Supplementary Tables 2-5). Overall, both bog and lagg bacterial communities were similar in terms of taxonomic composition and the relative abundances of phyla to other communities retrieved from Sphagnum peatlands around the northern hemisphere (Dedysh et al., 2006; Juottonen et al., 2005; Lin et al., 2012; Pankratov et al., 2005; Serkebaeva et al., 2013). Species richness, estimated using the Chao1 index, was consistently and significantly (ANOVA; F= $14.76, \mathrm{p}=0.002)$ higher in the lagg sites (2704 \pm 197 OTUs) than the bog sites $(2338 \pm 341$ 
OTUs). The control treatment also had significantly greater species diversity $(2747 \pm 221$ OTUs $)$ than the experimental $(2392 \pm 217$ OTUs, $\mathrm{p}=0.026)$ or recovery $(2425 \pm 426$ OTUs, $\mathrm{p}=0.043)$ treatments, which did not significantly differ from one another. Notably, the Desulfovibrionaceae and Syntrophobacteraceae that contain sulfate-reducing taxa, made up only a small fraction (0.00-0.0025\%; Supplementary Table 4) of the whole community, and did not differ significantly among treatments in either bog or lagg areas.

\subsection{Bacterial Community Responses to Sulfate Amendment}

The experimental manipulation of sulfate deposition had a significant impact on the composition of the whole bacterial community within the peatland. PERMANOVA analysis revealed that the lagg zone communities differed significantly among treatments $\left(\mathrm{F}_{(2,6)}=3.65, \mathrm{p}=0.003\right)$.

Hierarchical clustering analysis showed the recovery and control communities to be most similar, while the experimental communities were distinct (Figure 4a). In the bog areas, although the community clustering was visually less distinct than in the lagg (4b), bacterial communities did differ significantly among sulfate treatments $\left(\mathrm{F}_{(2,6)}=1.99, \mathrm{p}=0.019\right)$. The significantly greater taxonomic diversity of the lagg community suggests that it has a greater degree of ecological redundancy within functional groups, leading to greater resilience to sulfate perturbation than the bog community (Luck et al., 2003). In both lagg and bog areas, recovery and control Deltproteobacterial communities were highly similar to each other, but distinct from Deltproteobacterial communities in the experimental treatments. There was a composite cluster of communities from control and recovery treatments and a distant cluster composed solely of experimental communities (Figure 4c, d). These patterns were similar and significant in both lagg $\left(\mathrm{F}_{(2,6)}=3.600 \mathrm{p}=0.003\right)$ and $\operatorname{bog}\left(\mathrm{F}_{(2,6)}=3.138, \mathrm{p}=0.006\right)$ areas. 
The only previous work to investigate the effect of sulfate on an entire peatland bacterial community, rather than a metabolic or taxonomic subset, inferred changes in bacterial community structure by assessing changes in populations of bacterivorous testate amoebae (Payne et al., 2009). This indirect approach suggested that sulfate changed the bacterial community structure, a finding confirmed here using a replicated experimental manipulation of sulfate, paired with direct characterization of the bacterial community. The mechanism by which sulfate alters the peatland bacterial community appears to be relatively subtle, and further investigations are needed to link changes in the deposition of sulfate with specific taxonomic and functional changes. It is beyond the scope of this study to explain conclusively how sulfate changes bacterial communities; however, despite the apparent low abundance and responsiveness of confirmed SRB to sulfate treatments, results indicate that sulfate may directly alter the bacterial community structure through its effect on organisms that use it in their metabolism. Experimental sulfate additions may have stimulated unknown sulfate reducers, the full diversity of which is not described (Pester, 2012; Steger et al., 2011), or conferred a competitive advantage upon rare but disproportionately dominant sulfate reducers that have been estimated to carry out up to $50 \%$ of the anaerobic carbon mineralization in peatlands (Blodau et al., 2007; Keller and Bridgham, 2007), even when their abundance is very low (Andersen et al., 2013). Alternatively, it has been previously observed that changes in atmospheric sulfate inputs can restructure the bacterial community indirectly via mechanisms such as redirection of carbon flow away from methanogens (Gauci and Chapman, 2006; Lovley and Klug, 1983) with accompanying negative effects on methanotrophs, as well as stimulation of sulfide oxidizers as they consume the $\mathrm{H}_{2} \mathrm{~S}$ produced by sulfate reduction. Such a redirection of carbon flow with associated restructuring may be occurring in this system.

The effects of altered sulfate deposition regime on the bacterial community appear to be 
relatively short-lived and reversible. The recovery of bacterial communities in the lagg and near recovery in the bog within three years of the cessation of sulfate amendments suggests that the bacterial community structure is resilient to changes in the supply of labile sulfur. Similar findings were obtained by Seifert-Monson et al. (2014), who compared microbial enzyme activities in the former experimental area of the $\mathrm{S} 6$ peatland with newer microcosm sulfate amendments in the recovery and control areas. These authors observed no differences in enzyme activity between the former experimental area, which was in the process of recovering from sulfate amendment, and unamended control microcosms. At the time these authors sampled the S6 peatland, the experimental area had been unamended for approximately three years and was better considered a recovery treatment, suggesting that its microbial community was now functionally similar to that of the recovery treatment at the time it was sampled for this current study. In this experimental environment, added sulfate becomes increasingly recalcitrant as it is repeatedly recycled and progressively converted to less bioavailable organic forms (Coleman Wasik et al., 2012, 2015). Thus, most alterations to ecosystem function as a result of sulfatemediated changes in the bacterial community are hypothesized to be reversible on the timescale of a few years, although it should be noted that when sulfate deposition has been elevated for a longer time, the recovery period is also likely to be longer. This study specifically simulated the effects of historical reductions in sulfate deposition and suggests that emission reductions in North America and Europe over the last few decades have likely been sufficient for the peatland microflora to return to a structure similar to that found in areas with lower deposition.

\subsection{Relationship Between Sulfate-Mediated Changes in Bacterial Community Structure and MeHg}

The major purpose of this study was to investigate the impact of sulfate on the peatland bacterial 
community. However, the controlled field manipulation was originally conceived as an experimental investigation into the long-term effects of sulfate on MeHg production (Jeremiason et al., 2006), presenting an opportunity to explore whether bacterial community structure was related to $\% \mathrm{MeHg}$ in the peat. The percentage of mercury present as $\mathrm{MeHg}(\% \mathrm{MeHg})$ in peat integrates the long-term methylation and demethylation capacity of a soil, representing net $\mathrm{MeHg}$ accumulation (Drott et al., 2008). \% MeHg values correlated significantly with $\mathrm{MeHg}(r=0.900$, $\mathrm{p}<0.001)$, but not $\mathrm{THg}(r=-0.071, \mathrm{p}=0.781)$ concentrations in the peat, indicating that differences in $\% \mathrm{MeHg}$ are related to $\mathrm{MeHg}$ production and/or accumulation in peat and not a function of inorganic $\mathrm{Hg}$ content. As described more fully in previous work (Coleman Wasik et al., 2012, 2015; Jeremiason et al., 2006), sulfate deposition history did alter MeHg concentrations and $\% \mathrm{MeHg}$ in both the bog and the lagg areas (bog: $\mathrm{F}_{(2,6)}=20.16, \mathrm{p}=0.002$, lagg: $\mathrm{F}_{(2,6)}=$ $9.477, \mathrm{p}=0.014) . \% \mathrm{MeHg}$ was elevated in peat samples from both the bog and lagg areas of the experimental treatment $(8-16 \%)$, intermediate in the bog and lagg areas of the recovery treatments $(3-7 \%)$, and lowest in the control treatment in the bog area $(1-3 \%)$ (Figure 5). In the bog area, \% MeHg in the experimental treatment differed significantly from that in both the recovery and control, while the control and recovery were statistically similar to one another. In the lagg area, the experimental treatment had significantly greater $\% \mathrm{MeHg}$ than the recovery treatment, but the control site had unexpectedly high \% MeHg (9-10\%; Figure 5). This discrepancy was likely due to sampling a natural MeHg "hot spot" within the control area, as previously described by Mitchell et al. (2008) and Coleman-Wasik et al. (2012).

No correlation was found between the entire bacterial community structure and $\% \mathrm{MeHg}$ for either the lagg $(r=0.27, \mathrm{p}=0.10)$ or $\operatorname{bog}(r=-0.13, \mathrm{p}=0.53)$ areas. Although both mercury methylation and sulfate reduction capacity are found in non-Deltaprotoebacterial groups, approximately $78 \%$ of presently confirmed methylators are sulfate-reducing Deltaproteobacteria 
(Gilmour et al., 2013). Thus, Deltaproteobacteria were chosen as an additional focus for investigating how changes in $\% \mathrm{MeHg}$, which had been altered by experimental sulfate additions, may also be related to changes in the bacterial community structure of the S6 peatland. The Deltaproteobacteria were represented by 546 OTUs, which together comprised $2.5-7.8 \%$ of the weighted abundance per sample (Figure 3b). The most common of the eight Deltaproteobacterial orders present was Myxococcales, represented by 305 OTUs. Ten identified families, of which Syntrophobacteraceae and Cystobacteraceae were most abundant, were also found (Supplementary Table 5).

Unlike the whole bacterial community, Deltaproteobacterial communities did exhibit significant or nearly significant correlations with \% $\mathrm{MeHg}$ for both the bog and lagg areas (bog: Mantel $r=0.56, \mathrm{p}=0.008$, lagg: Mantel $r=0.36, \mathrm{p}=0.057)$. This relationship between Deltaproteobacterial community structure and \% $\mathrm{MeHg}$ suggests that the frequently-observed changes in MeHg production in response to sulfate (Branfireun et al., 1999; Coleman Wasik et al., 2012; Jeremiason et al., 2006; Mitchell et al., 2008) are likely related to changes in a subsection of the total bacterial community structure, but the moderate coefficients of variation indicate that this mechanism most likely occurs in addition to sulfate-mediated stimulation of SRB. Macaladay et al. (2000) found a strong relationship between $\mathrm{Hg}$ methylation rates and community structure of 37 SRB taxa identified using polar lipid fatty acid (PLFA) analysis in sediment from a California lake. Results from this current study extend this work through a more comprehensive accounting of the bacterial community and suggest that sulfate deposition is an important driver for mercury methylation, not simply because of augmented bacterial activity, but also due to controls on community structure.

108 OTU's from the lagg and 80 OTU's from the bog were identified that correlated significantly to \% MeHg levels in the peat (Supplementary Tables 6-7). Significant, positive 
correlations were found for several known methylating taxa. One OTU in Desulfovibrionaceae, a family hosting the best-known Hg-methylating genera (Compeau and Bartha, 1985; Gilmour et al., 2011) correlated significantly $(\mathrm{p}=0.007, r=0.817)$ with $\% \mathrm{MeHg}$, an interesting finding given the extremely low abundance of this family in the bacterial community $(0-0.25 \%)$. In addition, two OTUs in Syntrophobacteraceae, a Deltaproteobacterial family ( $\mathrm{p}=0.001-0.005, r$ $=0.888-0.833)$, and six OTUs in the Veillonellaceae family of the Firmicutes $(\mathrm{p}=0.007-0.001, r$ $=0.883-0.927)$, correlated with \%MeHg. Both of these groups contain taxa (Syntrophus aciditrophicus SB in Syntrophobacterales, and Desulfitobacterium metallireducens, Desulfosporosinus acidiphilus SJ4, Desulfitobacterium dehalogenans, Desulfosporosinus youngiae, Ethanoligenens harbinense YUAN-3, Dethiobacter alkaliphilus AHT 1 in Firmicutes) that have been recently identified in vitro as $\mathrm{Hg}$ methylators (Gilmour et al., 2013). Correlations observed are consistent with the hypothesis that these groups may methylate $\mathrm{Hg}$ in peat.

\section{Conclusion}

This work consistently supports the hypothesis that experimental increases and decreases in sulfate deposition lead to significant, but reversible, changes in the taxonomic composition of a peatland bacterial community. Furthermore, sulfate altered the community composition of the Deltaproteobacteria, and the structure of this community was correlated significantly with net $\mathrm{MeHg}$ accumulation. These results suggest a sulfate-mediated alteration of the Deltaproteobacteria community as a mechanism driving $\mathrm{MeHg}$ concentration changes in this peatland. Finally, it is notable that the experimental rate of sulfate deposition in this experiment simulated historical deposition in, and downwind of, industrial areas of eastern Canada and the US prior to aggressive regulation of sulfate emissions. Findings suggest that previous levels of pollution likely altered both the structure and at least one function ( $\mathrm{MeHg}$ production) of 
peatland bacterial communities, and that legislated emissions controls likely led to a significant lessening of these effects with a lag-time of well under a decade.

\section{Author Information}

\section{Corresponding Author}

Phone: +001 416208 2744; e-mail carl.mitchell@utoronto.ca

\section{Notes}

The authors declare no competing financial interest.

\section{Acknowledgements}

The authors gratefully acknowledge Shu-Yi Shen and the Qiime community for technical genomics advice, Plank Huang who carried out chemical analyses, and helpful advice from Daniel Jones. Additional thanks go to Jeff Jeremiason, Ed Swain, Bruce Monson, Jim Almendinger and Brian Branfireun for their participation in the sulfate-addition experiments, and Randy Kolka, Deacon Kyllander, and Carrie Dorrance of the Northern Research Station for administrative and field assistance throughout the course of the project. This publication was based on work funded by a Discovery Grant from the Natural Sciences and Engineering Research Council of Canada to CPJM, and the U.S. EPA-Science To Achieve Results (STAR) 
Program, Grant R827630, the Great Lakes Commission, Great Lakes Air Deposition Program, and the Minnesota Pollution Control Agency to DRE. These organizations had no role in the design, interpretation, or presentation of this project. The USDA Forest Service's Northern Research Station provided access to the study site as well as substantial in-kind support.

\section{References}

Allison, S.D., Martiny, J.B.H., 2008. Resistance, resilience, and redundancy in microbial communities. Proc. Natl. Acad. Sci. 105, 11512-11519. http://dx.10.1073/pnas.0801925105.

Amann, R.I., Ludwig, W., Scheifer, K.H., 1995. Phylogenetic identification and in situ detection of individual microbial cells without cultivation. Microbiol. Mol. Biol. Rev. 59, 143-169.

Andersen, R., Chapman, S.J., Artz, R.R.E., 2013. Microbial communities in natural and disturbed peatlands: a review. Soil Biol. Biochem. 57, 979-994.

http://dx.10.1016/j.soilbio.2012.10.003.

Anderson, M.J., 2001. A new method for non-parametric multivariate analysis of variance. Austral. Ecol. 26, 32-46. http://dx.10.1111/j.1442-9993.2001.01070.pp.x.

Bae, H.-S., Dierberg, F.E., Ogram, A., 2014. Syntrophs dominate sequences associated with the mercury methylation-related gene $h g c a$ in the water conservation areas of the Florida Everglades. Appl. Environ. Microbiol. 80, 6517-6526. http://dx.10.1128/AEM.01666-14.

Blodau, C., Mayer, B., Peiffer, S., Moore, T.R., 2007. Support for an anaerobic sulfur cycle in two Canadian peatland soils. J. Geophys. Res. 112, G02004.

http://dx.10.1029/2006JG000364.

Branfireun, B., Roulet, N., Kelly, C., Rudd, J., 1999. In situ sulphate stimulation of mercury methylation in a boreal peatland, toward a link between acid rain and methylmercury contamination in remote environments. Global Biogeochem. Cycles 13, 743-750.

Caporaso, J.G., Kuczynski, J., Stombaugh, J., Bittinger, K., Bushman, F.D., Costello, E.K., Fierer, N., Peña, A.G., Goodrich, J.K., Gordon, J.I., Huttley, G.A., Kelley, S.T., Knights, D., Koenig, J.E., Ley, R.E., Lozupone, C.A., McDonald, D., Muegge, B.D., Pirrung, M., Reeder, J., Sevinsky, J.R., Turnbaugh, P.J., Walters, W.A., Widmann, J., Yatsunenko, T., Zaneveld, J., Knight, R., 2010. QIIME allows analysis of high-throughput community sequencing data. Nat. Methods 7, 335-336. http://dx.10.1038/nmeth.f.303. 
Chao, A., 1984. Non-parametric estimation of the number of classes in a population. Scand. J. Stat. 11, 265-270.

Coleman Wasik, J.K., Mitchell, C.P.J., Engstrom, D.R., Swain, E.B., Monson, B.A., Balogh, S.J., Jeremiason, J.D., Branfireun, B.A., Eggert, S.L., Kolka, R.K., Almendinger, J.E., 2012. Methylmercury declines in a boreal peatland when experimental sulfate deposition decreases. Environ. Sci. Technol. 46, 6663-6671. http://dx.10.1021/es300865f.

Coleman Wasik, J.K., Engstrom, D.R., Mitchell, C.P.J., Swain, E.B., Monson, B.A., Balogh, S.J., Jeremiason, J.D., Branfireun, B.A., Kolka, R.K., Almendinger, J.E., 2015. The effects of hydrologic fluctuation and sulfate regeneration on mercury cycling in an experimental peatland: drought increases mercury in peatlands. J. Geophys. Res. Biogeosciences 120, 1697-1715. http://dx.10.1002/2015JG002993.

Compeau, G.C., Bartha, R., 1985. Sulfate-reducing bacteria: principal methylators of mercury in anoxic estuarine sediment. Appl. Environ. Microbiol. 50, 498-502.

Currey, P.M., Johnson, D., Sheppard, L.J., Leith, I.D., Toberman, H., Van Der Wal, R., Dawson, L.A., Artz, R.R.E., 2009. Turnover of labile and recalcitrant soil carbon differ in response to nitrate and ammonium deposition in an ombrotrophic peatland: enzyme response to $\mathrm{N}$ in peatlands. Glob. Change Biol. 16, 2307-2321. http://dx.10.1111/j.13652486.2009.02082.x.

Dedysh, S.N., Pankratov, T.A., Belova, S.E., Kulichevskaya, I.S., Liesack, W., 2006. Phylogenetic analysis and in situ identification of bacteria community composition in an acidic sphagnum peat bog. Appl. Environ. Microbiol. 72, 2110-2117. http://dx.10.1128/AEM.72.3.2110-2117.2006.

Drott, A., Lambertsson, L., Björn, E., Skyllberg, U., 2008. Do potential methylation rates reflect accumulated methyl mercury in contaminated sediments? Environ. Sci. Technol. 42, 153158. http://dx.10.1021/es0715851.

Edgar, R.C., 2010. Search and clustering orders of magnitude faster than BLAST. Bioinformatics 26, 2460-2461. http://dx.10.1093/bioinformatics/btq461.

Fuhrman, J.A., 2009. Microbial community structure and its functional implications. Nature, 459, 193-199. http://dx.10.1038/nature08058.

Gauci, V., Chapman, S.J., 2006. Simultaneous inhibition of CH4 efflux and stimulation of sulphate reduction in peat subject to simulated acid rain. Soil Biol. Biochem. 38, 35063510. http://dx.10.1016/j.soilbio.2006.05.011.

Gilmour, C.C., Elias, D.A., Kucken, A.M., Brown, S.D., Palumbo, A.V., Schadt, C.W., Wall, J.D., 2011. Sulfate-reducing bacterium Desulfovibrio desulfuricans nd132 as a model for understanding bacterial mercury methylation. Appl. Environ. Microbiol. 77, 3938-3951. http://dx.10.1128/AEM.02993-10 
Gilmour, C.C., Henry, E.A., Mitchell, R., 1992. Sulfate stimulation of mercury methylation in freshwater sediments. Environ. Sci. Technol. 26, 2281-2287.

Gilmour, C.C., Podar, M., Bullock, A.L., Graham, A.M., Brown, S.D., Somenahally, A.C., Johs, A., Hurt, R.A., Bailey, K.L., Elias, D.A., 2013. Mercury methylation by novel microorganisms from new environments. Environ. Sci. Technol. 47, 11810-11820. http://dx.10.1021/es403075t.

Griffiths, B.S., Philippot, L., 2012. Insights into the resistance and resilience of the soil microbial community. FEMS Microbiol. Rev. 37, 112-129. http://dx.10.1111/j.15746976.2012.00343.x.

Hamady, M., Lozupone, C., Knight, R., 2009. Fast UniFrac: facilitating high-throughput phylogenetic analyses of microbial communities including analysis of pyrosequencing and PhyloChip data. ISME J. 4, 17-27.

Hintelmann, H., Evans, R.D., 1997. Application of stable isotopes in environmental tracer studies - measurement of monomethylmercury $(\mathrm{CH} 3 \mathrm{Hg}+)$ by isotope dilution ICP-MS and detection of species transformation. Fresenius J. Anal. Chem. 358, 378-385. http://dx.10.1007/s002160050433.

Horvat, M.; Bloom, N.S.; Liang, L., 1993. Comparison of distillation with other current isolation methods for the determination of methyl mercury compounds in low level environmental samples. Part 1. Sediments. Anal. Chim. Acta. 281, 135-152.

Jeremiason, J.D., Engstrom, D.R., Swain, E.B., Nater, E.A., Johnson, B.M., Almendinger, J.E., Monson, B.A., Kolka, R.K., 2006. Sulfate addition increases methylmercury production in an experimental wetland. Environ. Sci. Technol. 40, 3800-3806. http://dx.10.1021/es0524144.

Juottonen, H., Galand, P.E., Tuittila, E.-S., Laine, J., Fritze, H., Yrjala, K., 2005. Methanogen communities and bacteria along an ecohydrological gradient in a northern raised bog complex. Environ. Microbiol. 7, 1547-1557. http://dx.10.1111/j.14622920.2005.00838.x.

Kahl, J.S., Stoddard, J.L., Haeuber, R., Paulsen, S.G., Birnbaum, R., Deviney, F.A., Webb, J.R., DeWalle, D.R., Sharpe, W., Driscoll, C.T., Herlihy, A.T., Gellogg, J.H., Murdoch, P.S., Roy, K., Webster, K.E., Urquhart, N.S., 2004. Have US surface waters responded to the 1990 Clean Air Act amendments? Environ. Sci. Technol. 38, 484A-490A.

Keller, J.K., Bridgham, S.D., 2007. Pathways of anaerobic carbon cycling across an ombrotrophic-minerotrophic peatland gradient. Limnol. Oceanogr. 52, 96-107.

Kunin, V., Engelbrektson, A., Ochman, H., Hugenholtz, P., 2010. Wrinkles in the rare biosphere: pyrosequencing errors can lead to artificial inflation of diversity estimates. Environ. Microbiol. 12, 118-123. http://dx.10.1111/j.1462-2920.2009.02051.x. 
Limpens, J., Berendse, F., Blodau, C., Canadell, J.G., Freeman, C., Holden, J., Roulet, N., Rydin, H., Schaepman-Strub, G., 2008. Peatlands and the carbon cycle: from local processes to global implications-a synthesis. Biogeosciences 5, 1475-1491.

Lin, X., Green, S., Tfaily, M.M., Prakash, O., Konstantinidis, K.T., Corbett, J.E., Chanton, J.P., Cooper, W.T., Kostka, J.E., 2012. Microbial community structure and activity linked to contrasting biogeochemical gradients in bog and fen environments of the glacial Lake Agassiz Peatland. Appl. Environ. Microbiol. 78, 7023-7031. http://dx.10.1128/AEM.01750-12.

Lovley, D.R., Klug, M.J., 1983. Sulfate reducers can outcompete methanogens at freshwater sulfate concentrations. Appl. Environ. Microbiol. 45, 187-192.

Lozupone, C., Knight, R., 2005. UniFrac: a new phylogenetic method for comparing microbial communities. Appl. Environ. Microbiol. 71, 8228-8235. http://dx.10.1128/AEM.71.12.8228-8235.2005.

Luck, G.W., Daily, G.C., Ehrlich, P.R., 2003. Population diversity and ecosystem services. Trends Ecol. Evol. 18, 331-336. http://dx.10.1016/S0169-5347(03)00100-9.

Macalady, J.L., Mack, E.E., Nelson, D.C., Scow, K.M., 2000. Sediment microbial community structure and mercury methylation in mercury-polluted Clear Lake, California. Appl. Environ. Microbiol. 66, 1479-1488. http://dx.10.1128/AEM.66.4.1479-1488.2000.

Mayewski, P.A., Lyons, W.B., Spencer, M.J., Twickler, M.S., Buck, C.F., Withlow, S., 1990. An ice-core record of atmospheric response to anthropogenic sulphate and nitrate. Nature $346,554-556$.

McArdle, B.H., Anderson, M.J., 2001. Fitting multivariate models to community data: a comment on distance-based redundancy analysis. Ecology 82, 290-297. http://dx.10.1890/0012-9658(2001)082[0290:FMMTCD]2.0.CO;2.

McKew, B.A., Taylor, J.D., McGenity, T.J., Underwood, G.J., 2011. Resistance and resilience of benthic biofilm communities from a temperate saltmarsh to desiccation and rewetting. ISME J. 5, 30-41.

Mitchell, C.P.J., Branfireun, B.A., Kolka, R.K., 2009. Methylmercury dynamics at the uplandpeatland interface: topographic and hydrogeochemical controls. Water Resour. Res. 45, http://dx.10.1029/2008WR006832.

Mitchell, C.P.J., Branfireun, B.A., Kolka, R.K., 2008. Spatial characteristics of net methylmercury production hot spots in peatlands. Environ. Sci. Technol. 42, 1010-1016. http://dx.10.1021/es0704986.

Munthe, J., Bodaly, R.A., Branfireun, B.A., Driscoll, C.T., Gilmour, C.C., Harris, R., Horvat, M., Lucotte, M., Malm, O., 2007. Recovery of mercury-contaminated fisheries. AMBIO J. Hum. Environ. 36, 33-44. http://dx.10.1579/0044-7447(2007)36[33:ROMF]2.0.CO;2. 
Muyzer, G., Stams, A.J.M., 2008. The ecology and biotechnology of sulphate-reducing bacteria. Nat. Rev. Microbiol. 6, 441-454. http://dx.10.1038/nrmicro1892.

National Atmospheric Deposition Program/National Trends Network, 2006. Annual \& seasonal data summary for Site MN16. http: //nadp.sws.uiuc.edu/ads/2006/MN16.pdf.

Nelson, T.M., Streten, C., Gibb, K.S., Chariton, A.A., 2015. Saltwater intrusion history shapes the response of bacterial communities upon rehydration. Sci. Total Environ. 502, 143148. http://dx.10.1016/j.scitotenv.2014.08.109.

Pak, K.-R., Bartha, R., 1998. Mercury methylation by interspecies hydrogen and acetate transfer between sulfidogens and methanogens. Appl. Environ. Microbiol. 64, 1987-1990.

Pankratov, T.A., Belova, S.E., Dedysh, S.N., 2005. Evaluation of the phylogenetic diversity of prokaryotic microorganisms in sphagnum peat bogs by means of fluorescence in situ hybridization (FISH). Microbiology 74, 722-728.

Payne, R., Gauci, V., Charman, D.J., 2009. The impact of simulated sulfate deposition on peatland testate amoebae. Microb. Ecol. 59, 76-83. http://dx.10.1007/s00248-009-9552-6.

Pennanen, T., Fritze, H., Vanhala, P., Kiikkilä, O., Neuvonen, S., Bååth, E., 1998. Structure of a microbial community in soil after prolonged addition of low levels of simulated acid rain. Appl. Environ. Microbiol. 64, 2173-2180.

Pester, M., 2012. Sulfate-reducing microorganisms in wetlands - fameless actors in carbon cycling and climate change. Front. Microbiol. 3. http://dx.10.3389/fmicb.2012.00072.

Price, M.N., Dehal, P.S., Arkin, A.P., 2010. FASTTREE 2 - approximately maximum-likelihood trees for large alignments. PLoS ONE 5, e9490. http://dx.10.1371/journal.pone.0009490.

Ramette, A., 2007. Multivariate analyses in microbial ecology: Multivariate analyses in microbial ecology. FEMS Microbiol. Ecol. 62, 142-160. http://dx.10.1111/j.15746941.2007.00375.x.

Ranchou-Peyruse, M., Monperrus, M., Bridou, R., Duran, R., Amouroux, D., Salvado, J.C., Guyoneaud, R., 2009. Overview of mercury methylation capacities among anaerobic bacteria including representatives of the sulphate-reducers: implications for environmental studies. Geomicrobiol. J. 26, 1-8. http://dx.10.1080/01490450802599227.

Scheffer, M., Carpenter, S., Foley, J.A., Folke, C., Walker, B., 2001. Catastrophic shifts in ecosystems. Nature 413, 591-596.

Schmalenberger, A., Drake, H.L., Küsel, K., 2007. High unique diversity of sulfate-reducing prokaryotes characterized in a depth gradient in an acidic fen. Environ. Microbiol. 9, 1317-1328. http://dx.10.1111/j.1462-2920.2007.01251.x. 
Seifert-Monson, L.R., Hill, B.H., Kolka, R.K., Jicha, T.M., Lehto, L.L., Elonen, C.M., 2014. Effects of sulfate deposition on pore water dissolved organic carbon, nutrients, and microbial enzyme activities in a northern peatland. Soil Biol. Biochem. 79, 91-99. http://dx.10.1016/j.soilbio.2014.09.007.

Serkebaeva, Y.M., Kim, Y., Liesack, W., Dedysh, S.N., 2013. Pyrosequencing-based assessment of the bacteria diversity in surface and subsurface peat layers of a northern wetland, with focus on poorly studied phyla and candidate divisions. PLoS ONE 8, e63994. http://dx.10.1371/journal.pone.0063994.

Steger, D., Wentrup, C., Braunegger, C., Deevong, P., Hofer, M., Richter, A., Baranyi, C., Pester, M., Wagner, M., Loy, A., 2011. Microorganisms with novel dissimilatory (bi)sulfite reductase genes are widespread and part of the core microbiota in low-sulfate peatlands. Appl. Environ. Microbiol. 77, 1231-1242. http://dx.10.1128/AEM.01352-10.

Vile, M.A., Bridgham, S.D., Wieder, R.K., Novák, M., 2003. Atmospheric sulfur deposition alters pathways of gaseous carbon production in peatlands: $\mathrm{S}$ deposition alters gaseous $\mathrm{c}$ production in peatlands. Glob. Biogeochem. Cycles 17, http://dx.10.1029/2002GB001966.

Yu, R.-Q., Adatto, I., Montesdeoca, M.R., Driscoll, C.T., Hines, M.E., Barkay, T., 2010. Mercury methylation in sphagnum moss mats and its association with sulfate-reducing bacteria in an acidic Adirondack forest lake wetland. FEMS Microbiol. Ecol. 74, 655668. http://dx.10.1111/j.1574-6941.2010.00978.x. 


\section{Figure Captions}

Figure 1 Field Site: Diagram of the sulfate amendment experiment in the S6 peatland of the Marcell Experimental Forest. Black arrows indicate the direction of water flow. Inset map indicates location of the Marcell Experimental Forest in north-central Minnesota, U.S.A. Sulfate amendment schedule is summarized in the lower left corner for reference.

Figure 2 Sulfate Concentrations: Sulfate levels $\left(\mathrm{mg} \mathrm{l}^{-1}\right)$ in porewater from the experimental (Exp.), recovery (Rec.) and control (Cont.) treatments of the lagg and bog areas of the S6 peatland five months after the final sulfate amendment in 2008.

Figure 3 Bacterial Communities: Taxonomy and average relative abundance in each treatment from the lagg (left) and bog (right) areas for the total bacterial community (a) and the Deltaproteobacteria (b). Phyla level results are presented for the overall bacterial community, with low abundance phyla (less than $0.5 \%$ of the weighted abundance in any treatment) subsumed into the Bacteria classification for clarity. Deltaproteobacterial taxa are weighted by the relative abundance within the Deltaproteobacteria rather than the whole bacterial community and are presented at the lowest taxonomic level (phylum, class, or order) to which they could be assigned.

Figure 4 Clustering of Bacterial Communities: Weighted-UNIFRAC based hierarchical clustering trees of bacterial communities sequenced from peat cores obtained from different sulfate amendment treatments $(\mathrm{E}=$ experimental; $\mathrm{R}=$ recovery; $\mathrm{C}=$ control). From top left: overall bacterial communities from the lagg (a) and bog (b) areas, and Deltaproteobacterial communities of the lagg (c) and bog (d). 
Figure 5 Methylmercury Accumulation: The mean percentage of total $\mathrm{Hg}$ as $\mathrm{MeHg}(\% \mathrm{MeHg})$ \pm standard deviation in peat cores from the three sulfate treatments $($ Exp. $=$ experimental; Rec. $=$ recovery; Cont. $=$ control $)$. The probabilities $(\mathrm{p} \leq 0.05)$ associated with each pairwise comparison are indicated above the relevant pair of columns. 
Figure 2 (Single Column)

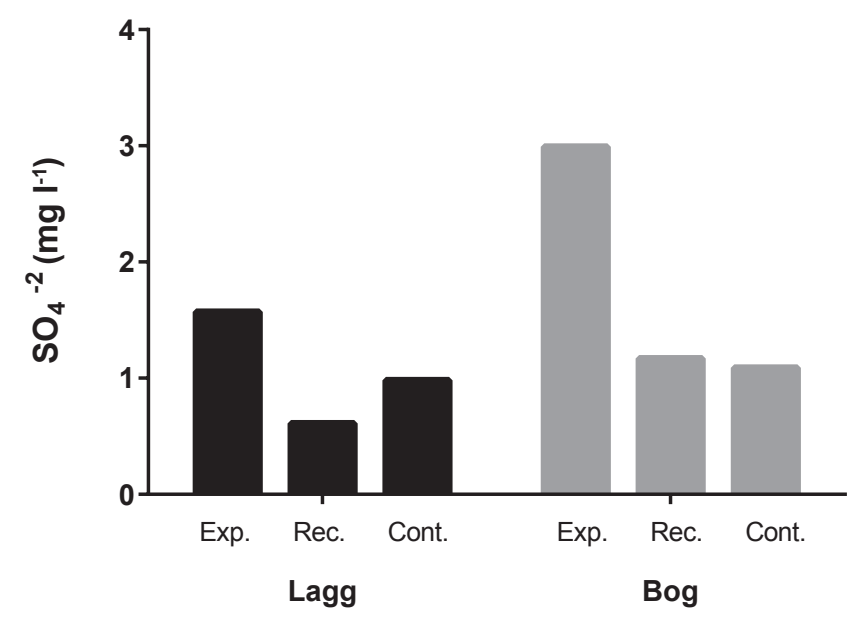


Figure 3 (Double Column)

a) Total community

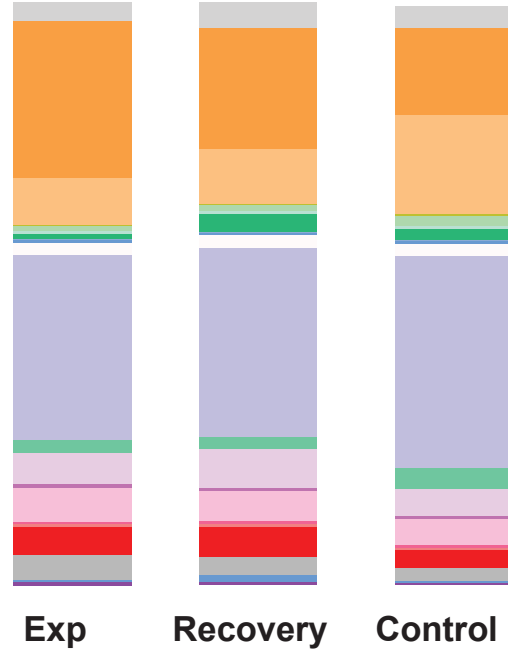

Lagg

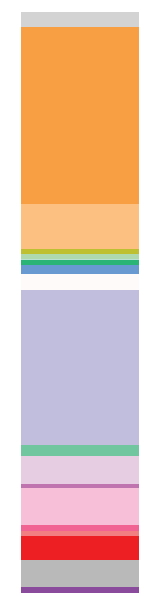

Exp

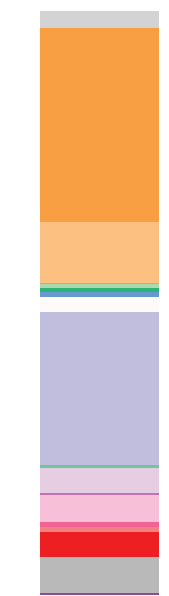

Recovery
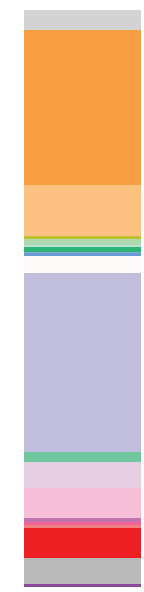

Control
- Bacteria

- Actinobacteria

- Acidobacteria

- Armatimonadetes

Bacteriodetes

- Chlorobi

- Chloroflexi

Elusimicrobia

- Firmicutes

- Gemmatimonadales

Planctomyctes

- Alphaproteobacteria

- Betaproteobacteria

- Deltaproteobacteria

- Gammaproteobacteria

- Proteobacteria other

- TM7

TM6

- Verruocomicrobia

WPS-2

- AD3

Bog

\section{b) Deltaproteobacteria}
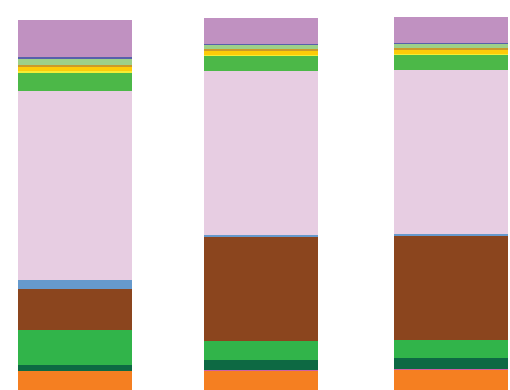

Exp

Recovery

Control

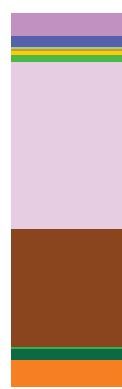

Exp

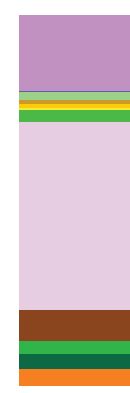

Recovery

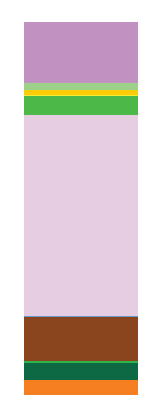

Control
M1Z46

- Desulfovibrionales

Deltaproteobacteria

- Syntrophorhabdaceae

Bdellovibrionaceae

CTD005-82B-02

- Geobacteraceae

Myxococcales

Myxococcales: Cystobacteraceae

Myxococcales: Haliangiaceae

Myxococcaceae

- Polyangiaceae

- Syntrophobacterales

- Syntrophaceae

- Syntrophobacteraceae 
Figure 4 (Single Column)

LAG G
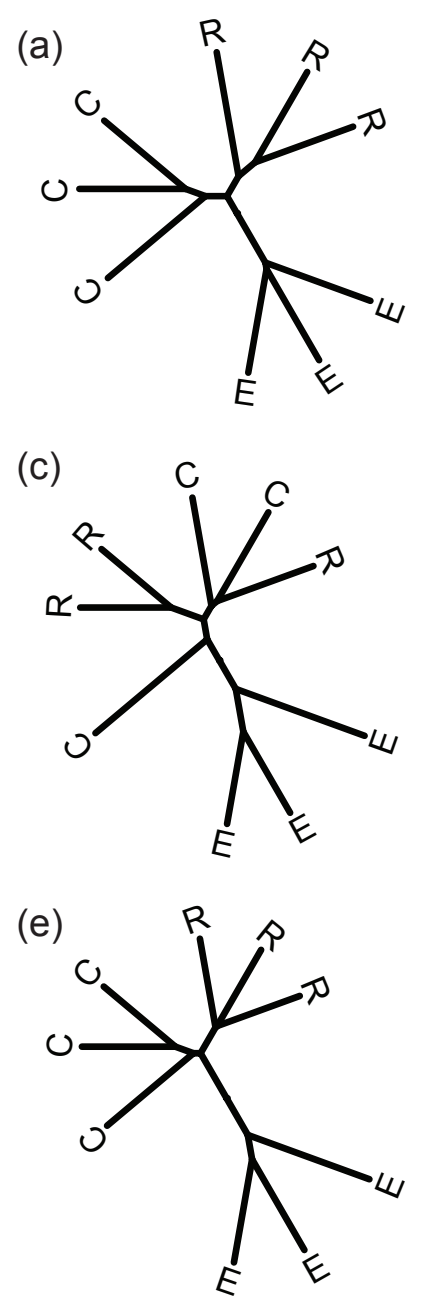

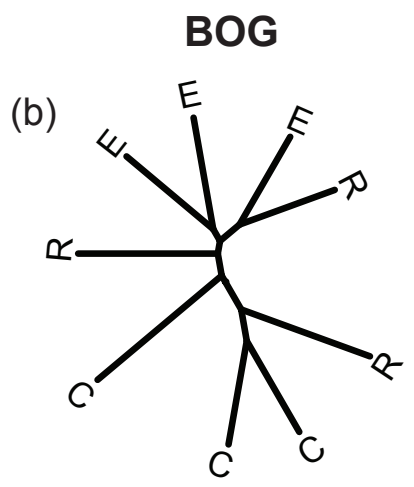

(d)
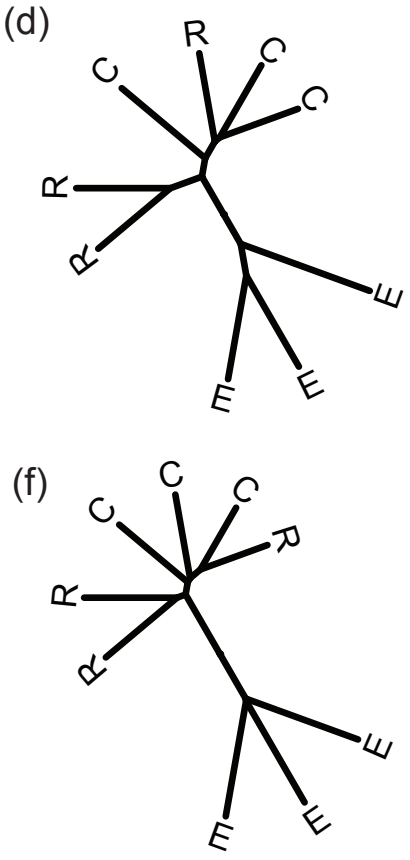
Figure 5 (Single Column)

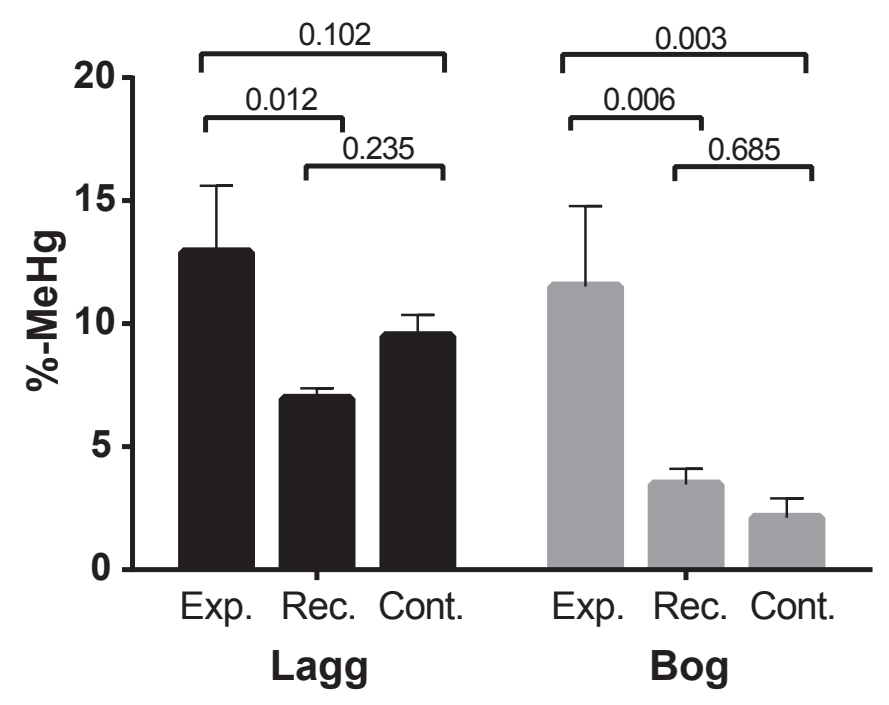




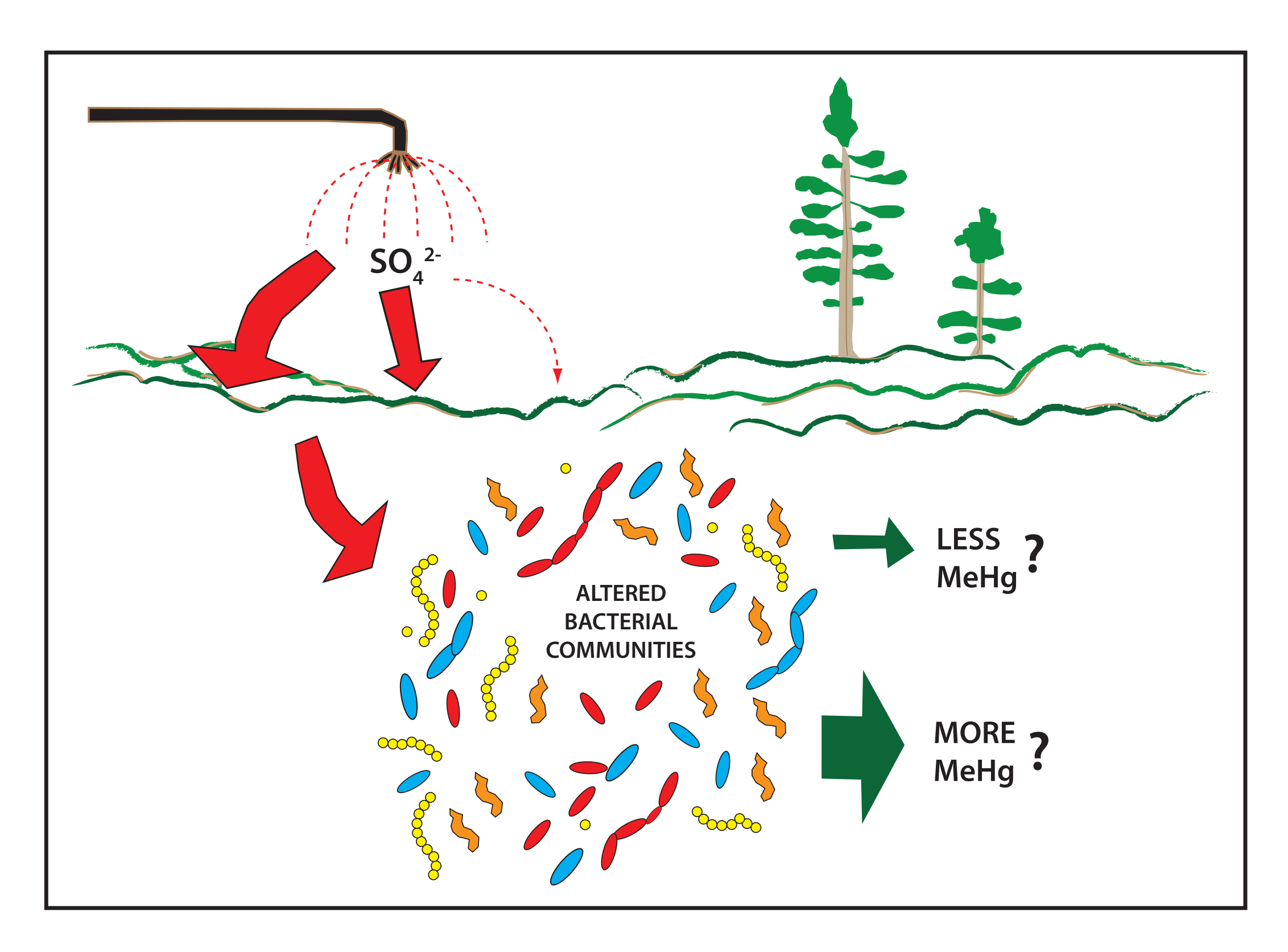

